Revue d'histoire de l'Amérique française

Q REVUE D.HISTOIRE DE L'AMÉRIQUE FRANÇAISE

\title{
BERNARD (Frère Antoine) C.S.V., Les Clercs de Saint-Viateur au \\ Canada. Le premier demi-siècle 1847 à 1897, Montréal, Les \\ Clercs de Saint-Viateur, 1947, 650 p. carte et ill.
}

\section{Un professeur de Bourget}

Volume 1, numéro 1, juin 1947

URI : https://id.erudit.org/iderudit/801358ar

DOI : https://doi.org/10.7202/801358ar

Aller au sommaire du numéro

Éditeur(s)

Institut d'histoire de l'Amérique française

ISSN

0035-2357 (imprimé)

1492-1383 (numérique)

Découvrir la revue

Citer ce compte rendu

Un professeur de Bourget (1947). Compte rendu de [BERNARD (Frère Antoine)

C.S.V., Les Clercs de Saint-Viateur au Canada. Le premier demi-siècle 1847 à

1897, Montréal, Les Clercs de Saint-Viateur, 1947, 650 p. carte et ill.] Revue

d'histoire de l'Amérique française, 1(1), 134-135.

https://doi.org/10.7202/801358ar d'utilisation que vous pouvez consulter en ligne.

https://apropos.erudit.org/fr/usagers/politique-dutilisation/ 
BERNARD (Frère Antoine) C.S.V., Les Clercs de Saint-Viateur au Canada. Le premier demi-siècle 1847 à 1897, Montréal, Les Clercs de Saint-Viateur, 1947, 650 p. carte et ill.

Dans un fort volume de quelque six cents pages, le Frère Antoine Bernard, c.s.v., retrace les origines de l'Institut des Clercs de Saint-Viateur et raconte le premier demi-siècle de son histoire au Canada (1847-1897). La préface est du T. Révérend Père P.-Emile Farley, alors supérieur général des C.S.V., décédé depuis.

C'est une œuvre d'une belle ordonnance et de haute tenue littéraire; on y reconnaît l'écrivain déjà rompu à la méthode historique, qui sait mettre en valeur des documents écrits de première main, en tenant compte de l'élément humain qui prend une place si importante dans l'interprétation des faits.

Après les quatre premiers chapitres sur les origines, l'auteur groupe les événements par étapes de dix ans; chaque étape comprend deux chapitres dont l'un présente l'histoire du développement général de la communauté au pays et l'autre, celle des principales fondations: le noviciat et le collège de Joliette, le collège Bourget de Rigaud, le collège de Berthier, l'Institution des Sourds-Muets et l'Académie St-Jean-Baptiste de Montréal...

La pages les plus captivantes de l'œuvre sont celles qui font revivre un personnage comme le Père Louis Querbes, fondateur de l'Institut en France, Monseigneur Bourget, le saint évêque qui le transplanta en terre canadienne, le Père Champagneur et ses compagnons, M. Barthélemy Joliette, M. le curé Manseau... Quelle merveilleuse histoire que la rencontre du Père Querbes et de Monseigneur Bourget ! Deux 
hommes faits pour s'entendre, deux apôtres passionnés du bien des âmes, désireux de fournir une aide efficace au clergé paroissial et des éducateurs à la jeunesse.

Durant ce demi-siècle, Monseigneur Bourget, créateur inlassable, fut le centre de toutes les activités de la jeune communauté. C'est à son appel que les Clercs de Saint-Viateur vont fonder dans toutes les parties de son vaste diocèse. L'auteur entre dans tous les détails: motifs des fondations, causes des échecs; rien n'échappe à son analyse, tout est rapporté avec franchise et interprété dans le meilleur esprit. L'auteur met en regard les idées souvent contradictoires des intéressés en éducation, les désirs légitimes ou les ambitions exagérées de certains curés, la sympathique compréhension ou la mesquinerie des populations, la pénurie de personnel et la multiplicité des œuvres, la pauvreté des sujets et leur générosité sans bornes.

"Ce qui frappera d'abord, dit la préface, c'est la part constante et intime qu'ont prise ces humbles religieux à la vie de toutes les localités où ils ont travaillé ")... En ce sens, l'ouvrage déborde son titre; il est plus qu'un livre de famille. Il intéressera le grand public, parce qu'il a été rédigé avec largeur de vue et qu'il repose sur des documents de première main

Un professeur de Bourget. 